\title{
Comparison of IGRF Models with North American Magnetic Data*
}

\author{
E. Dawson and L. R. NewitT \\ Division of Seismology and Geomagnetism, Earth Physics Branch, \\ Energy, Mines and Resources, Ottawa, Canada
}

(Received March 12, 1982)

\begin{abstract}
Comparisons of proposed and adopted geomagnetic reference field models are made against North American test data for the period 1965 to 1985. These test data ( $X, Y, Z$, and $F$ ) include Canadian map and aeromagnetic data and USGS land-based data. Model values are also tested against predicted component values for 1982 and 1984 derived from 27 magnetic observatories on or near the North American continent.

These tests indicate that all candidate models provide an excellent fit to North American test data at epochs 1965, 1970, and 1975. Only the USGS and NASA models fit these data satisfactorily at 1980. The best secular variation models for 1980-1985 appear to be the IGS and USGS models.

Finally, our tests indicate that the recently adopted series of reference field models provides a reasonable and satisfactory fit to North American test data.
\end{abstract}

\section{Introduction}

In 1979 in Canberra the IAGA working group on the analysis of the geomagnetic field (WGI-1) agreed on a new format for the International Geomagnetic Reference Field (IGRF). This format is outlined by PEDDIE (1980). Three institutes submitted sets of models as proposed updates of the IGRF: the U. K. Institute of Geological Sciences (IGS) (BARraclough et al., 1982), the U.S. Geological Survey (USGS) (PedDIE and Fabiano, 1982) and the U.S. National Aeronautics and Space Administration (NASA) (LANGEL $e t$ al., 1982). Tests of these proposed models for the period 1965-1984 against North American magnetic data were presented at the 4th IAGA Scientific Assembly, Edinburgh, 1981. Since then the coefficients of the adopted models have been distributed. These models, DGRF, etc. (e.g., IAGA DIVISION I WORKING Group 1, 1981), are collectively referred to in our paper as IGRF (new). The original reference models, IGRF 1965 and IGRF 1975 are referred to as IGRF (old). The results of tests of these models against North American magnetic data are presented.

\section{Comparison of Proposed Models}

Prior to testing models against North American three-component magnetic data, a comparison of the spherical harmonic coefficients of the proposed models was made. The

\footnotetext{
*Contributions from the Earth Physics Branch No. 1021.
} 
USGS models were arbitrarily chosen as reference models and differences were obtained between their coefficients and those from other institutes. The IGRF (old) was also used. The maximum degree and order $(N M A X)$ of the coefficients are ten for most of the main field models and are eight for the secular variation (SV) models. The exceptions are the IGS 1965 and the IGRF (old) main field models whose $N M A X=8$. Rms deviations were derived. The results of this coarse comparison are given in Table 1.

As expected, the deviations of the IGRF (old) from the USGS coefficients increase with time. On the whole, the coefficients of the IGS models deviate more from those of the USGS models than do the NASA models. This deviation is particularly pronounced for the 1980 epoch. The agreement between the USGS and NASA models improves with time. In the period 1980-1985, the IGS time terms are in closer agreement with those of the USGS than the NASA terms. We would expect to see all of these characteristics reflected in tests using North American data.

Table 1. Rms deviation of spherical harmonic coefficients (in nT) (USGS minus other models).

\begin{tabular}{ccccc}
\hline \multirow{2}{*}{ Epoch } & $\begin{array}{c}\text { Coefficients } \\
\text { (main field) }\end{array}$ & IGRF (old) & IGS & NASA \\
\hline \multirow{2}{*}{1965} & $\mathrm{~g}$ & 9 & 5 & 5 \\
1970 & $\mathrm{~h}$ & 7 & 5 & 5 \\
& $\mathrm{~g}$ & 15 & 5 & 5 \\
1975 & $\mathrm{~h}$ & 8 & 4 & 4 \\
\multirow{2}{*}{1980} & $\mathrm{~g}$ & 24 & 5 & 3 \\
& $\mathrm{~h}$ & 17 & 9 & 1 \\
& $\mathrm{~g}$ & 24 & 10 & 1 \\
$1980-85$ & $\mathrm{~h}$ & 18 & 1.2 & 1.7 \\
& $(\mathrm{SV}$ field) & 1.8 & 0.9 & 1.8 \\
\hline
\end{tabular}

\section{Test Data}

Values of $D, H$, and $Z$ were scaled from a series of national magnetic charts of Canada for epochs 1965,1970 , and 1975 at a constant latitude interval of $5^{\circ}$ and a longitude interval varying from $5^{\circ}$ at latitude $40^{\circ} \mathrm{N}$ to $20^{\circ}$ at latitude $85^{\circ} \mathrm{N}$. A total of 150 values in each component for each epoch were obtained. $X, Y$, and $F$ were calculated from these values.

A comparable set of national magnetic charts of Canada for 1980 were not available. For this epoch we utilized a dense distribution of approximately 9,900 three-component data in $X, Y$, and $Z$ that were partially used to derive a magnetic declination chart of Canada (DA wson et al., 1981) and to test scalar and vector Magsat data (NEwITT et al., 1982). Figure 1 shows the distribution of these data. Eighty-four percent are from the Earth Physics airborne surveys 1959-1976. The remaining data were obtained from the USGS. All data were reduced to epoch 1980 using SV information from 20 magnetic observatories and 109 magnetic repeat stations in North America (DA wSON et al., 1981). The overall rms error in the SV reduction is approximately $21 \mathrm{nT}$. 


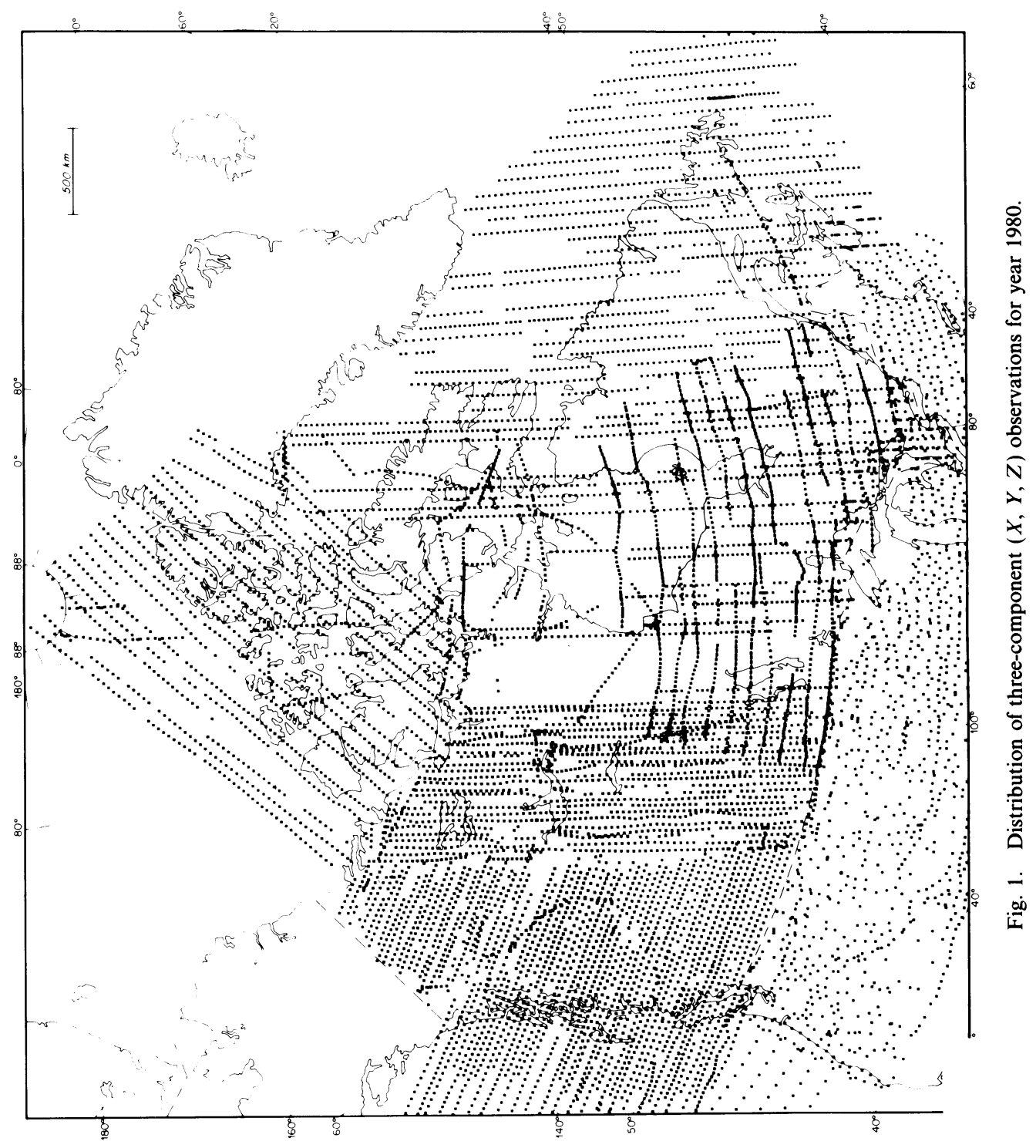


To test the predictive ability of the proposed models, values for 1982 and 1984 in components $X, Y, Z$, and $F$, were extrapolated from linear least square fits to observatory annual mean differences for the interval 1975-1980. Twenty-seven observatories on or near the North American continent were used to obtain 54 predicted values in each component for these tests.

\section{Test Results}

The rms deviations of the $X, Y, Z$, and $F$ test data from the various models are given in Table 2. The test results for IGRF (new) are also given.

These results show what most users are aware of, that the performance of the IGRF (old) as a standard model, has been hopelessly deteriorating since the early 1970's. They also show that the Canadian national magnetic charts for 1975 closely resemble the magnetic field reflected by the proposed models.

Although none of the proposed models best fit the test data in all components at all epochs, the IGS models give the best overall fit prior to 1975, and the USGS and NASA from 1975 on. The deterioration of the IGS fit in 1980 is probably due to the fact that the original main field model, on which it is based, was designed primarily to fit the angular elements of the field $(D, I)$.

These results also show that the IGRF (new) model provides an excellent compromise for the period 1965 to 1980 .

The predictive ability of these models for the period 1980 to 1984 is shown in Table 3 .

Table 2. Rms deviation of model values from main field test data (in $\mathrm{nT}$ ).

\begin{tabular}{|c|c|c|c|c|c|}
\hline Epoch & IGRF (old) & IGS & USGS & NASA & IGRF (new) \\
\hline \multicolumn{6}{|c|}{$X$} \\
\hline 1965 & 151 & 136 & 139 & 136 & 135 \\
\hline 1970 & 148 & 144 & 153 & 155 & 148 \\
\hline 1975 & 212 & 80 & 74 & 74 & 75 \\
\hline 1980 & 216 & 184 & 154 & 154 & 154 \\
\hline \multicolumn{6}{|c|}{$Y$} \\
\hline 1965 & 147 & 145 & 146 & 139 & 142 \\
\hline 1970 & 149 & 144 & 146 & 145 & 144 \\
\hline 1975 & 160 & 108 & 112 & 116 & 112 \\
\hline 1980 & 257 & 185 & 173 & 174 & 172 \\
\hline \multicolumn{6}{|c|}{$Z$} \\
\hline 1965 & 188 & 175 & 177 & 178 & 179 \\
\hline 1970 & 195 & 204 & 208 & 213 & 207 \\
\hline 1975 & 198 & 106 & 105 & 107 & 103 \\
\hline 1980 & 363 & 228 & 153 & 152 & 151 \\
\hline \multicolumn{6}{|c|}{$F$} \\
\hline 1965 & 178 & 162 & 169 & 170 & 169 \\
\hline 1970 & 186 & 193 & 200 & 206 & 198 \\
\hline 1975 & 196 & 99 & 99 & 102 & 97 \\
\hline 1980 & 326 & 228 & 148 & 147 & 148 \\
\hline
\end{tabular}


Table 3. The Rms deviation of predicted SV at north american observatories from various models over the period 1980 to 1984 (in $\mathrm{nT}$ ).

\begin{tabular}{cccccc}
\hline Component & IGRF (old) & IGS & USGS & NASA & IGRF (new) \\
\hline$X$ & 23 & 6 & 6 & 16 & 6 \\
$Y$ & 28 & 5 & 3 & 11 & 4 \\
$Z$ & 51 & 13 & 12 & 25 & 12 \\
$F$ & 52 & 12 & 13 & 27 & 12 \\
\hline
\end{tabular}

It is obvious that the IGS and USGS predictive models best fit our predicted values for North American observatories. Again the IGRF (new) model provides a reasonable compromise.

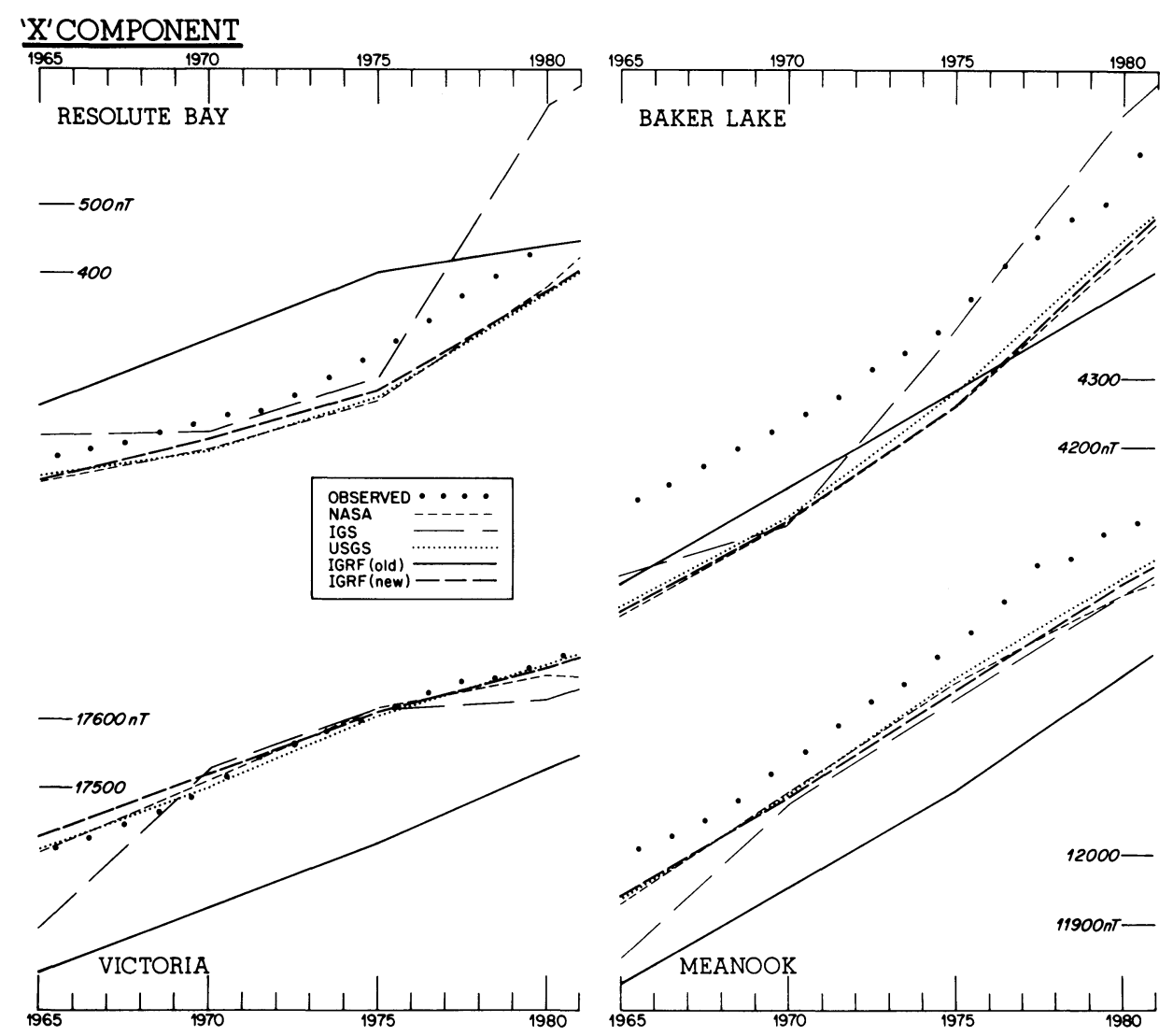

Fig. 2. Comparison of model values to observatory annual mean values in $X$ for the period 1965 to 1980 . 

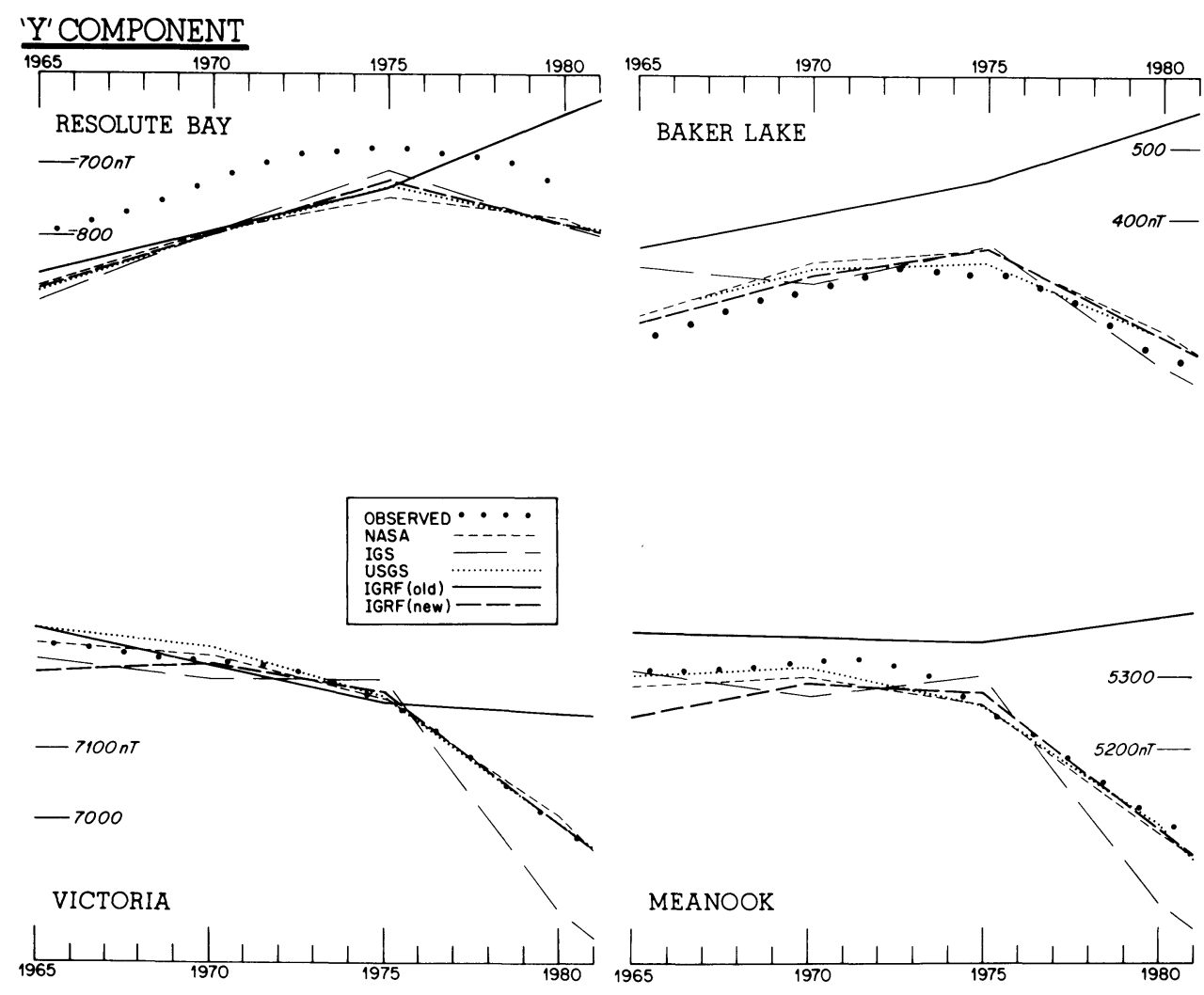

Fig. 3. Comparison of model values to observatory annual mean values in $Y$ for the period 1965 to 1980 .

\section{Graphical Values}

Accurate interpolation between epochs is a necessary and practical requirement for a reference field. The proposed models and the IGRF's (old and new) were tested, assuming a linear interpolation of magnetic component values between epochs. Annual mean values in $X, Y, Z$, and $F$ from 1965 to 1980 from 20 North American observatories were used as test data. Figures 2 to 4 show graphs of the fit of the model values to annual mean values in $X, Y$, $Z$ for four representative Canadian observatories only. The results for $F$ (not shown) are quite similar to those of $Z$.

These graphs depict four main points.

1. In general, the proposed models tend to fit the observed data better than the IGRF (old).

2. In all components, the USGS and NASA model values are similar.

3. There is a tendency for IGS values to meander.

4. It appears that the IGRF (new) provides an excellent compromise. 


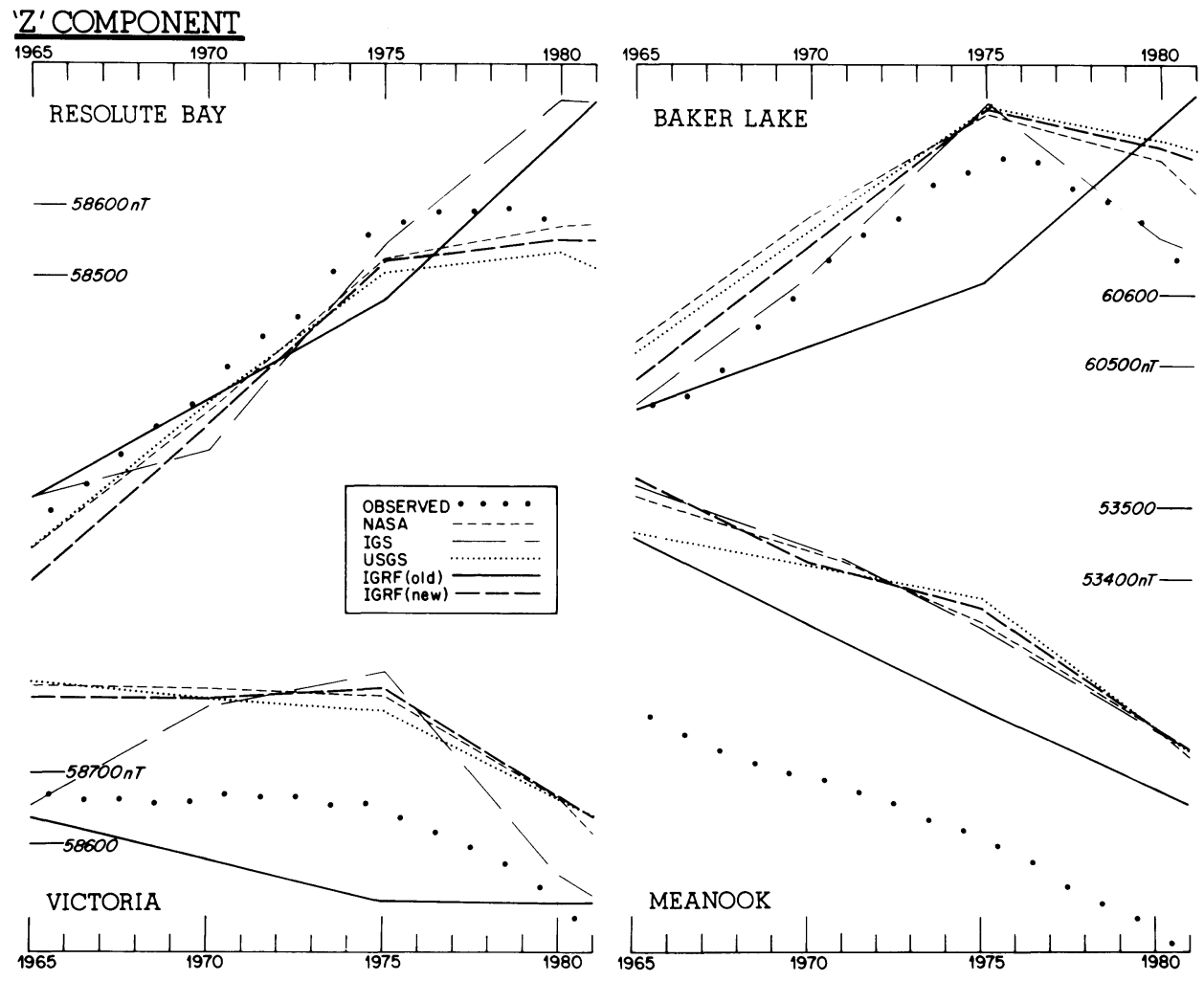

Fig. 4. Comparison of model values to observatory annual mean values in $Z$ for the period 1965 to 1980 .

\section{Conclusions}

All the candidate models provide an excellent fit to North American test data at epochs 1965, 1970, and 1975. For 1980, only the USGS and NASA models fit these data satisfactorily. The best predictive SV models for 1980-85 appear to be the IGS and USGS models.

The apparent meandering of the IGS interpolated graphical values points out the necessary requirement for consistency between models at different epochs. There were two reasons for this meandering. The first is due to interpolation complications between models of different degree and order at 1965 and 1970. The second one, dealing with special purpose models, has already been mentioned.

Finally our tests indicate that the IGRF (new) provides a reasonable and satisfactory fit to North American test data, and should be a sound basis on which to add future reference fields. 


\section{REFERENCES}

Barraclough, D. R., B. M. Hodder, and S. R. C. Malin, The IGS proposal for the new International Geomagnetic Reference Field, J. Geomag. Geoelectr., this issue, 351-356, 1982.

Peddie, N. W., Report of Working Group I-1 : Analysis of the main field and secular variations, IAGA News, No. 1Y, p. 50 , December 1980.

Da wson, E., L. R. Newitt, A. NANDI, and D. NAGY, A spherical harmonic approach to mapping the magnetic declination in Canada for 1980, Geomag. Ser., 21, pp. 19, Earth Phys. Br., E. M. R., Ottawa, 1981.

IAGA DIVISION I WORKING GRoup 1, International Geomagnetic Reference Fields: DGRF 1965, DGRF 1970 , DGRF 1975, and IGRF 1980, EOS Trans. AGU, 62, 1169, 1981.

LANGel, R. A., R. H. Estes, and G. D. MEAD, Some new methods in Geomagnetic field modeling applied to the 1960-1980 epoch, J. Geomag. Geoelectr., this issue, 327-349, 1982.

Newitt, L. R., E. Dawson, R. L. Coles, and A. NANDi, Magnetic charts of Canada derived from Magsat data, Geophys. Res. Lett., 9, 246-249, 1982.

Peddie, N. W. and E. B. Fabiano, A proposed International Geomagnetic Reference Field for 1965-1985, J. Geomag. Geoelectr., this issue, 357-364, 1982. 